\title{
A Study on the Teaching and Learning of DPL5013 Fundamentals of Supply Chain Management Using Innovative Practical Games at Metro Johor Bahru Polytechnic
}

\author{
Hazlin Binti Jamari \\ Academic Department \\ Politeknik METrO Johor Bahru \\ Johor, Malaysia \\ hazlinpmjb@gmail.com
}

\begin{abstract}
This paper aims to study the teaching and learning Fundamentals of Supply Chain Management for Diploma in Logistics and Supply Chain students using innovative practical games. The researchers carried out action research in producing valid data and valuable insights for this study. This research paper presents a new practical game that helps Diploma students to understand how the concept of supply chain management works. This game uses the course structure of DPL5013 Fundamentals of Supply Chain Management which contains three supply chain entities, namely suppliers, factories, and customers, which covers six theoretical topics of this course. The game uses a board game such as a physically shaped snake checkers carving and contains game rules such as each player's responsibilities and product descriptions. The game uses several sets of questions that can determine the successful winner. Bloom's taxonomy was used as a guideline to develop this assessment test based on course learning outcomes. The proposed board game was tested by a group of 62 Diploma in Logistics and Supply Chain Management students at METrO Johor Bahru Polytechnic who took the DPL5013 Fundamentals of Supply Chain Management course for the June 2020 session. More than 70\% exceeding the target of the Academic Department, PMJB which is $50 \%$. In addition, most students have a positive view of the game.
\end{abstract}

Keywords-supply chain game, innovative teaching, and learning, action research

\section{INTRODUCTION}

In this modern era, the teaching and learning process is increasingly complex. The chalk and talk method are no longer relevant. Longo and Mirabelli [1], stated the Supply Chain is highly dynamic, encompassing customer networks, suppliers, partners, ordering processes and demand anticipation methods, inventory control policies, and item combinations by overcoming challenges including complexity, uncertainty, risk, visibility, collaboration, cost, and sustainable management.

According to Mustafee and Katsaliaki [2], their study, most importantly, was to educate academics including students to understand how dynamic the SCM situation is. This is a very difficult task. Textbooks, case studies, and traditional lectures are enough as a basis to help students understand the fundamentals of supply chain management. However, it still fails to envision the real situation of the supply chain and the strategic decisions required. Through this environment, it is difficult for students to see from a manager's perspective, which involves decisions being made and seeing the real impact. Using practical games or business games in lectures makes it a different pedagogical option that can help to better understand the theories learned in class. Therefore, lecturers need to have the initiative to apply more creative and innovative teaching and learning process. Accordingly, on this initiative, a product or teaching and learning innovation have been produced namely the Supply Chain Game. It meets the needs of today's students to study in a more relaxed state and without feeling stressed. The Fundamentals of Supply Chain Management (SCM) course is a field course for semester 3 students of the Diploma in Logistics and Supply Chain Management (DLS) at METrO Johor Bahru Polytechnic and requires students to achieve four-course learning outcomes (CLO) namely:-

CLO 1: Describe clearly the basic concepts of supply chain management, strategic sourcing, and customer relationship management in supply chain activities among services and manufacturing companies. 
CLO 2: Explain the major element of lean and Six Sigma as integral parts of supply chain management

CLO 3: Analyze precisely the buyer-supplier relationship and performance measurement for successful supply chain management:

CLO 4: Classify the issues that related to current trends and the future of supply chain management based on an organized assigned group project in industrial visit

To achieve the four learning outcomes of this course, an Innovative Practical Game at METrO Johor Bahru Polytechnic was introduced called Supply Chain Game.

\section{SUPPLy CHAIN GAME}

\section{A. Background}

This Supply Chain Game means a practical supply chain game. It is a project that has been produced to shape a game that follows the SCM syllabus. The game is produced to interest the students in this course and also hone the students 'skills in answering the given questions. The game was inspired by the classic game (snake checkers). Snake Checkers is now considered a classic board game that is loved by children around the world. This game has been very popular since time immemorial with the advent of tools and technology. While the game is known to most people, not many people know about the history and origins of how the game was made. Snake Dam is an invention of ancient Indian society and is not played as mere entertainment. Initially, this Snake Checkers game was known by several names such as 'Mokshapat', 'Moksha Patamu' or the most popular was 'Gyan Chaupar' (meaning game of knowledge). The game is played with several players running the game in turns. Each numbered box is accompanied by a question and participants must answer correctly to the end and win. Through this game, lecturers can get the way students answer with the knowledge and skills they have to survive in the game as well as know the understanding of the players answering the Fundamentals of Supply Chain Management syllabus questions.

Therefore, this study was conducted to see the extent of the achievement of teaching and learning Fundamental Supply Chain Management by using the Innovative Practical Game that is Supply Chain Game at METrO Johor Bahru Polytechnic.

\section{B. Research objective}

The objective of this study was to see what the achievements were;

CLO 1: Describe clearly the basic concepts of supply chain management, strategic sourcing, and customer relationship management in supply chain activities among services and manufacturing companies.
CLO 2: Explain the major element of lean and Six Sigma as integral parts of supply chain management

CLO 3 Analyze precisely the buyer-supplier relationship and performance measurement for successful supply chain management:

CLO 4: Classify the issues related to current trends and the future of supply chain management based on an organized assigned group project in the industrial visit. after using the practical Supply Chain Game.

\section{LITERATURE REVIEW}

Teaching methods for Supply Chain Management courses are now showing a development. This issue is on the rise among the Supply Chain Management academic community. Zeng and Johnson [3] stated many lecturers in business and engineering faculties use supply chain games for example Beer Games and Supply Chain Simulator to support teaching and learning for SCM courses. Half of SC games can be played on computers or boards and physical components. The Beer Game has become one of the most popular teaching methods. It is a simulation of the flow of materials and information through a computer among four entities in a series of supply chains: factories, distributors, wholesalers, and retailers. The main benefit of Beer Game is to help students understand the existence and characteristics of the "bullwhip effect". However, many experts criticize this Beer Game simulation. Kaminsky and Simchi-Levi [4] stated Beer Game has many shortcomings among which students are generally tied to the mechanism of the game which can affect the actual supply chain scenario. Kimbrough [5] stated a lack of motivation to improve during the game as players are not encouraged to share information. Chen and Samroengraja [6] reported in their study that players do not know the demand process and the type of distribution. Zeng and Johnson [3] reported in their study findings, found that this Beer Game simulation game is not effective for Diploma students to improve their understanding of the course. So there is still a gap to research to make this game improve.

In this game proposal, it is necessary to take into account the involvement of students in the game as they are in their actual role as supply chain players. Hopefully, the students who play can be encouraged to share information with the players in the supply chain. Intensive face-to-face communication for information sharing between players in a team can be implemented. The player as a manufacturer can inform the requirements of parts or components to the player who plays the character of the supplier and vice versa in any probability of problems encountered.

Zeng and Johnson [3] reported other Supply Chain games are dominated by technology fundamentals and often require relevant knowledge and students who have passed the pre-requisites of the courses. However, 
Diploma students who have never been exposed to this Supply Chain Management course find it difficult to relate the theoretical knowledge of SCM with practice as it is something complicated and complex and the occurrence of uncertainty. Therefore, it is necessary to develop a new game Supply Chain Games specifically for Diploma students and below.

\section{RESEARCH METHODOLOGY}

The analysis of this study uses the PMJB ispmp examination system. Evaluation data includes all evaluation requirements enshrined in the Fundamentals of Supply Chain Management course syllabus. Data were analyzed for the course implementation period which is from 20 June 2020 to 16 February 2021 using the PMJB ispmp examination system. The number of respondents is a class for the June 2020 study session, namely DLS Semester 3, PMJB's Diploma in Logistics and Supply Chain Management program, totaling 62 people.

\section{FINDINGS AND CONCLUSION}

The results of the study found that the average achievement of CLO learning outcomes 1, 2, 3, and 4 courses is more than $70 \%$. The achievement of CLO 1 is $73 \%$. CLO 2 is $80 \%$, CLO 3 is $76 \%$ and CLO 4 is $79 \%$. The highest achievement is CLO 2 which is $80 \%$. Students' skills to explain the key elements of Lean and Six Sigma in Supply Chain Management.

TABLE I. THE ACHIEVEMENT Of COURSE LEARNING OUTCOME (CLO)

\begin{tabular}{|c|c|c|c|}
\hline & & $\begin{array}{l}\text { Group } \\
\text { Attainment } \\
\quad(\%)\end{array}$ & $\begin{array}{l}\text { KPI } \\
(\%)\end{array}$ \\
\hline CLO 1 & $\begin{array}{l}\text { Describe clearly the basic concepts of supply chain management, strategic sourcing, and } \\
\text { customer relationship management in supply chain activities among services and } \\
\text { manufacturing companies. }\end{array}$ & 73 & 50 \\
\hline CLO 2 & $\begin{array}{l}\text { Explain the major element of lean and Six Sigma as integral parts of supply chain } \\
\text { management }\end{array}$ & 80 & 50 \\
\hline CLO 3 & $\begin{array}{l}\text { Analyze precisely the buyer-supplier relationship and performance measurement for } \\
\text { successful supply chain management }\end{array}$ & 76 & 50 \\
\hline CLO 4 & $\begin{array}{l}\text { Classify the issues related to current trends and the future of supply chain management } \\
\text { based on an organized assigned group project in industrial visit }\end{array}$ & 79 & 50 \\
\hline
\end{tabular}

Teaching and learning based on creative and effective teaching methods and techniques through the use of learning aids, innovative able to stimulate students to learn. Lecturers who are positive will accept change as a challenge in their profession. Lecturers are dynamic, efficient and always strive to advance teaching and learning in the classroom by designing teaching techniques and producing interesting teaching aids. Teaching methods should be varied according to the needs of students who have different levels of knowledge to facilitate students to understand the teaching. After the survey is conducted, this innovative product or teaching and learning can not only help students who have learning difficulties, it can also be used as a strengthening and enrichment activity for students who have mastered a certain knowledge. It also helps students 'skills in group activities, injects student motivation and lecturer-student interaction.

\section{ACKNOWLEDGMENT}

High appreciation to the Management of PMJB, Graduate Employability Division of the Department of Polytechnic Education, and Community College Malaysia for the strong support given to complete the alumni satisfaction survey on the curriculum and facilities at PMJB

\section{REFERENCES}

[1] Longo, F., and G. Mirabelli. 2008. "An Advanced Supply Chain Management Tool based on Modeling and Simulation." Computers \& Industrial Engineering 54:570-588.

[2] Mustafee, N., and K. Katsaliaki. "The Blood Supply Game." In Proceedings of the 2010 Winter Simulation Conference, edited by B. Johansson, S. Jain, J. Montoya-Torres, J. Hugan, and E. Yücesan, 327-338. Piscataway, New Jersey: Institute of Electrical and Electronics Engineers, Inc.

[3] Zeng, A., \& Johnson, S. 2009. Integrating a discovery-based laboratory to teach supply chain management fundamentals in an undergraduate management course. Innovations in Education and Teaching International, 461, 71-82. doi:10.1080/14703290802646305.Google ScholarCross Ref

[4] Kaminsky, P., \& Simchi-Levi, D. 1998. A new computerized beer game: A tool for teaching the value of integrated supply chain management. Global supply chain and technology management, 11, 216-225.Google Scholar

[5] Kimbrough, S., Wu, D., \& Zhong, F. 2002. Computers play the beer game: Can artificial agents manage supply chains? Decision Support Systems, 333, 323-333. doi:10.1016/S016792360200019-2. Google ScholarDigital Library

[6] Chen, F., \& Samroengraja, R. 2000. The stationary beer game. Production and Operations Management, 91, 19-30. doi:10.1111/j.1937-5956.2000.tb00320.x.Google Scholar. 